\title{
Role of Matrix Metalloproteinase-2 in Newborn Mouse Lungs under Hypoxic Conditions
}

\author{
NAMASIVAYAM AMBALAVANAN, TEODORA NICOLA, PENG LI, ARLENE BULGER, \\ JOANNE MURPHY-ULLRICH, SUZANNE OPARIL, AND YIU-FAI CHEN

\begin{abstract}
Department of Pediatrics [N.A., T.N., A.B.], Department of Cell Biology [N.A.], Department of Medicine [P.L., S.O., Y.-F.C],
\end{abstract} \\ Department of Pathology [J.M.-U.], University of Alabama at Birmingham, Birmingham, AL 35233
}

\begin{abstract}
Hypoxia impairs normal neonatal pulmonary artery remodeling and alveolar development. Matrix metalloproteinase-2 (MMP-2), which regulates collagen breakdown, is important during development. Our objective was to test the hypothesis that hypoxia attenuates the normal postnatal increase in MMP-2 and evaluate alveolar development and pulmonary arterial remodeling in

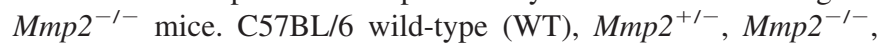
and MMP-inhibited (with doxycycline) mice were exposed to hypoxia $\left(12 \% \mathrm{O}_{2}\right)$ or air from birth to 2 wk of age. Pulmonary arterial remodeling, alveolar development, and vascular collagen and elastin were evaluated. MMP-2 was estimated by quantitative real-time polymerase chain reaction, enzyme-linked immunosorbent assay, immunohistochemistry, and zymography. We observed that 1) in WT mice, hypoxia led to thicker-walled pulmonary arteries and impaired alveolarization, accompanied by decreased MMP-2 and increased tissue inhibitor of metalloproteinases-2 (TIMP-2); 2) $M m p 2^{-1-}$ mice in air had thicker-walled arteries, impaired alveolarization, and increased perivascular collagen and elastin compared with WT; 3) hypoxia further inhibited alveolarization but did not alter arterial thickening in $M m p 2^{-/-}$mice. $M m p 2^{+/-}$and MMP-inhibited mice also had thicker-walled arteries than WT in air, but alveolarization was not different. We conclude that hypoxia reduces the postnatal MMP-2 increase in the lung, which may contribute to abnormal pulmonary arterial remodeling and impaired alveolarization. (Pediatr Res 63: 26-32, 2008)
\end{abstract}

$\mathrm{C}$ hronic hypoxia leads to abnormal pulmonary arterial remodeling with excessive collagen and elastin deposition (1), similar to that observed in persistent pulmonary hypertension of the newborn (2), bronchopulmonary dysplasia (BPD) (3), and congenital heart disease $(4,5)$. Chronic hypoxia also permanently inhibits alveolar development $(6,7)$, which normally begins in late gestation in humans and postnatally in mice $(8,9)$.

The hypoxia-induced effects on pulmonary arterial remodeling and alveolarization suggest that hypoxia alters extracellular matrix (ECM) turnover. Matrix metalloproteinases (MMPs) regulated by tissue inhibitors of metalloproteinases (TIMPs) regulate ECM turnover (10), and only specific MMPs can initiate collagen breakdown (11). The gelatinases (MMP-2

Received May 15, 2007; accepted August 21, 2007

Correspondence: Namasivayam Ambalavanan, M.D., 525 New Hillman Building., University of Alabama at Birmingham, 619 South 20th Street, Birmingham, AL 35233; e-mail: ambal@uab.edu

Funded in part by NICHD K08 HD046513, ATS PH-06-006, CCRI Dr Rud Polhill grant, a Research Facilities Improvement Program Grant C06 RR 15490, and National Heart, Lung, and Blood Institute Grants HL-44195, HL-50147, HL-45990, HL-07457, HL-56046. and MMP-9) degrade collagen more efficiently than other MMPs (12). MMP-2 is the predominant gelatinase in the developing lung (13), and the fetal human lung has a proteolytic profile with higher MMP-2 compared with the adult lung (14). Pro-MMP-2 (72 kD) is converted to an active form (66 $\mathrm{kD})$ that in turn cleaves many substrates, including collagen, fibronectin, and elastin (15). The other gelatinase, MMP-9, is chiefly expressed by inflammatory and epithelial cells (16) and not by pulmonary arteries (17). MMP-2 activity is primarily regulated at the level of activation of pro-MMP-2 by TIMP-2 and MMP-14 (18-20). TIMP-2 potentiates MMP-2 activation at low concentrations and inhibits it at higher concentrations (21).

In the current study, we focused on MMP-2 because of its substrate specificity, presence in large amounts in the developing lung, and localization in pulmonary arteries. We hypothesized that hypoxia reduces the high levels of MMP-2 that are required for normal neonatal pulmonary arterial remodeling and alveolarization, leading to persistent fetal-like, thicker-walled arteries and impaired alveolar development.

\section{METHODS}

All protocols were approved by the institutional animal care and use committee. All experiments were performed with at least six samples for each experimental condition.

Animal models. Mmp $2^{-/-}, \mathrm{Mmp}^{+/-}$, and wild-type (WT, $\mathrm{Mmp2}^{+/+}$) $\mathrm{C} 57 \mathrm{BL} / 6$ mice were exposed to normobaric $12 \% \mathrm{O}_{2}$ (hypoxia) or air (normoxia) from birth with their dam for $2 \mathrm{wk}$, as described previously (22). The Mmp $2^{-1-}$ mouse (23) was kindly provided by Drs. David Corry and Farrah Kheradmand, Baylor College of Medicine, Houston, TX. Similar air and hypoxic exposures were performed in WT mice given doxycycline (MMP-2 inhibitor). Doxycycline was administered at $20 \mu \mathrm{g} / \mathrm{g}$ body weight intraperitoneally daily (5 $\mu \mathrm{L}$ volume), similar to doses used in adult animals (24). After completion of air or hypoxia exposures, lungs were inflation-fixed and the right ventricle (RV) perfused with $10 \%$ formalin at $20 \mathrm{~cm} \mathrm{H}_{2} \mathrm{O}$ pressure. Coronal $5 \mu \mathrm{m}$ sections from apex to base of both lungs were made.

Lung morphometry. For all measurements, all slides were stained at the same time, and observers were masked to slide identity.

Immunohistochemical staining. Immunohistochemical staining was performed using a primary antibody for pro-MMP-2 and a horseradish peroxidase-labeled streptavidin biotin kit (LabVision Corporation, Fremont, CA). Nonspecific immunoglobulin $\mathrm{G}$ and omission of primary antibody were used as controls. Six $\times 400$ fields from six mice per group were evaluated. Thresholds for positive antibody staining in comparison with nonimmune

Abbreviations: BPD, bronchopulmonary dysplasia; ECM, extracellular matrix; MMP-2, matrix metalloproteinase-2 (gelatinase A); MMP-14, matrix metalloproteinase-14 (MT1-MMP); TIMP-2, tissue inhibitor of metalloproteinases-2 
serum controls were defined using image analysis software (MetaMorph v.6.2, Universal Imaging Corporation, Downingtown, PA). Positive pixels were expressed as percentages of total tissue area, excluding air spaces (25).

Alveolar development. Alveolar development was evaluated by mean linear intercepts (MLI) (26) and radial alveolar counts (RAC) (27). Six $\times 100$ hematoxylin-eosin-stained lung fields per mouse were evaluated. To understand the temporal sequence of alveolar development, lungs from $1 \mathrm{~d}, 14 \mathrm{~d}$, young adult (8-12 wk) mice were analyzed.

Vascular morphometry. For vascular morphometry, pulmonary arteries $20-150 \mu \mathrm{m}$ in external diameter were analyzed in $\times 400$ fields. At least 20 pulmonary arteries were evaluated per section (22). The wall thickness (\%) of each artery was expressed as a percentage of the vessel diameter:

Wall thickness $(\%)=100 \times(2 \times$ wall thickness $) /$ external diameter

The thickness of the RV compared with that of the left ventricle (RV/LV free wall thickness ratio) was determined as an index of RV hypertrophy (22). $\mathrm{RV}$ pressures are difficult to measure in newborn mice, and $\mathrm{RV}$ pressures were measured only in adult $M m p 2^{-1-}$ and WT mice by RV needle puncture.

Vascular collagen and elastin. Vascular collagen and elastin were measured in sections stained with picric acid Sirius red or Verhoeff's elastic tissue stain, respectively, by image analysis (28). Collagen staining was measured and expressed as a percentage of the total vessel and perivascular area, and elastin staining was measured and expressed as a percentage of the vessel area. Twenty arteries were evaluated per section.

Measurements of MMP-2, TIMP-2, and MMP-14. Zymograms and reverse zymograms. Lungs were homogenized in $1 \mathrm{~mL}$ of T-PER (Pierce, Rockford, IL) and centrifuged at $12,000 \times g$ for $5 \mathrm{~min}$. The supernatant was analyzed for gelatinases by zymography and for TIMPs by reverse zymography. Similar protein concentrations $(10 \mu \mathrm{g} / \mathrm{lane})$ were loaded on gels. Zymograms (10\% w/gelatin) or reverse zymograms (10\% w/gelatin +3.5 $\mu \mathrm{g} / 10 \mathrm{~mL}$ MMP-2) were renatured, developed, and Coomassie blue stained and destained as per standard protocol (BioRad, Hercules, CA). Zymograms detect pro-MMP-2 and active MMP-2 not associated with TIMP-2. Reverse zymograms detect TIMPs as a darker band where the TIMPs prevent the MMP-2 incorporated in the gel from gelatin digestion. Quantitation was performed by densitometry in comparison with known standards.

Measurements of MMP-2, TIMP-2, and MMP-14. Enzyme-linked immunosorbent assay. Active and total MMP-2 were measured by enzyme-linked immunosorbent assay (ELISA; Amersham Pharmacia Biotech, Piscataway, NJ). Total MMP-2 was measured by addition of p-aminophenylmercuric acetate, which fully activates pro-MMP-2. The amount of active MMP-2 detected by ELISA reflects active MMP-2 not bound to TIMP-2 in vivo.

Measurements of MMP-2, TIMP-2, and MMP-14. Quantitative real-time polymerase chain reaction. RNA was extracted using Trizol from homogenized whole mouse lung, and quantitative real-time polymerase chain reaction (PCR) was performed using the Bio-Rad iCycler System as described previously (29). The primer sequences were MMP-2: sense: 5' CCCCGATGCTGATACTGA 3' and antisense $5^{\prime}$ CTGTCCGCCAAATAAACC 3'; TIMP-2: sense: 5' CACGCTTAGCATCACCCA $3^{\prime}$ and antisense $5^{\prime}$ TGACCCAGTCCATCCAGAG $3^{\prime}$; MMP-14: sense 5' GCAGTATGGCTACCTACCTCC $3^{\prime}$ and antisense 5' TTGCCTGTCACTTGTAAACC $3^{\prime}$; and 18S RNA: 5'-GTCTGCCCTATCAACTTTCG-3' and 5'-ATGTGGTAGCCGTTTCTCA-3'.

\section{RESULTS}

MMP-2 and TIMP-2 in developing mouse lung. Mmp $2^{-1-}$ mice had a survival disadvantage because, of the first 100 survivors beyond $1 \mathrm{wk}$ of age, only 35 (35\%) were $\mathrm{Mmp2}^{-/-}$, and of the subsequent 180 survivors, 57 (32\%) were $\mathrm{Mmp}^{-1-}$ (against an expected $50 \%$ from breeding $\mathrm{Mmp2}^{+/-}$with ${ }^{-/-}$mice). Mortality in $\mathrm{Mmp2}^{-1-}$ mice was maximal on $\mathrm{d} 1$ and comparable with WT thereafter, indicating no healthy survivor effect after $\mathrm{d} 1$.

Immunohistochemical analysis of WT air mouse lungs demonstrated pro-MMP-2 staining in the perivascular area, the tunica media, and intima, as well as in the interstitium (Fig. 1A). The pro-MMP-2 staining was reduced in WT mice exposed to hypoxia (Fig. $1 A, B$, and $C$ ). Zymograms showed that total and active MMP-2 increased in WT air lung extracts from $1 \mathrm{~d}$ to $3 \mathrm{~d}$ and remained elevated through $14 \mathrm{~d}$ (Fig. 1D). Hypoxia attenuated this normal postnatal increase in total and active MMP-2 (Fig. 1D). Reductions in total and active MMP-2 by hypoxia at 3 and $14 \mathrm{~d}$ were confirmed by ELISA (Fig. $1 E$ and $F$ ). MMP-2 mRNA was lower in WT hypoxia compared with WT air lungs at $1 \mathrm{~d}$ but not at subsequent time points (Fig. 1G). MMP-9 was detected in lung extracts (Fig. $1 D$ ), but densitometric quantitation of the MMP-9 did not reveal statistically significant effects of postnatal age or hypoxia, although there was a trend toward increase on d $3(P=$ $0.18)$.

Administration of doxycycline reduced total MMP-2 (control $160 \pm 14 v s$ doxycycline $104 \pm 16 \mathrm{ng} / \mathrm{mL} / \mathrm{mg}$ protein, $p<0.05$ ) as well as active MMP-2 (control $52 \pm 4 v \mathrm{vs}$ doxycycline $41 \pm 5 \mathrm{ng} / \mathrm{mL} / \mathrm{mg}$ protein, $p<0.05$ ) as measured by ELISA in lung extracts at $14 \mathrm{~d}$. At $14 \mathrm{~d}$, both TIMP-2 protein concentrations (Fig. $2 A$ and $B$ ) and TIMP-2 mRNA expression were higher in WT hypoxia than in WT air lungs (Fig. 2C). TIMP-2 protein levels increased in both WT air and WT hypoxia lungs from 3 to $14 \mathrm{~d}$ (Fig. $2 B$ ).

MMP-14 mRNA increased from 1 to $3 \mathrm{~d}$ and then decreased by $14 \mathrm{~d}$ in WT air lungs (data not shown). MMP-14 was decreased on hypoxic exposure at $1 \mathrm{~d}$ but was similar to air control at subsequent time points (data not shown).

MMP-2 absence impairs alveolarization. At $14 \mathrm{~d}$ of age, WT mice in air had small alveoli with numerous secondary crests (Fig. 3A), and hypoxic WT mice had larger alveoli and reduced septation (Fig. 3B). Mmp $2^{-1-}$ air mice had large alveoli (Fig. 3C), and hypoxia further increased alveolar size in this genotype (Fig. 3D). Increased MLI and a lower RAC were noted in WT hypoxia mice and $M m p 2^{-1-}$ air mice compared with WT air mice (Fig. $3 E$ and $F$ ). Hypoxia further increased MLI and reduced RAC in $\mathrm{Mmp2}^{-1-}$ mice. Alveolar development and the effects of hypoxia in doxycyclineexposed and $M m p 2^{+/-}$mice were not different from WT mice (Fig. $3 E$ and $F$ ).

At $1 \mathrm{~d}$ of age, alveolar development was similar in WT and $M m p 2^{-\prime-}$ mice (Fig. 3G). MLI decreased with advancing age in both genotypes. $M m p 2^{-1-}$ mice in air had greater MLI than WT air mice at both $14 \mathrm{~d}$ and $8-12$ wk of age, indicating persistence of impaired alveolar development.

MMP-2 deficiency leads to thicker-walled pulmonary arteries but not $R \boldsymbol{V}$ hypertrophy. At $14 \mathrm{~d}$ of age, WT air mice had thin-walled pulmonary arteries (Fig. $4 A$ and $E$ ), and WT hypoxic mice had thicker-walled arteries (Fig. $4 B$ and $E$ ). $M m p 2^{-/-}$air mice had thicker-walled arteries (Fig. $4 C$ and $E$ ), and hypoxia did not further increase pulmonary arterial thickness in this genotype (Fig. $4 D$ and $E$ ). Hypoxia increased $\mathrm{RV} / \mathrm{LV}$ thickness ratio in WT mice and in $M m p 2^{-/-}$mice (Fig. $4 F$ ). Despite the increased pulmonary arterial thickness noted in $\mathrm{Mmp2}^{-1-}$ air mice, the RV/LV thickness ratio in $M m p 2^{-1-}$ air mice was not different from the WT air mice. Wall thickness and RV/LV thickness ratio at $14 \mathrm{~d}$ in doxycycline-exposed and $\mathrm{Mmp2}^{+/-}$air mice were not different from $M m p 2^{-l-}$ air mice, with thicker-walled pulmonary arteries than WT air mice but no RV hypertrophy (Fig. $4 E$ and $F$ ).

$M m p 2^{-1-}$ air mice had thicker-walled pulmonary arteries than WT at $1 \mathrm{~d}$ and $14 \mathrm{~d}$, but this increase did not persist into adult life (Fig. 4G). In air-exposed adult mice of both genotypes, RV pressures were similar (median, $6 \mathrm{~mm} \mathrm{Hg}$; range, 

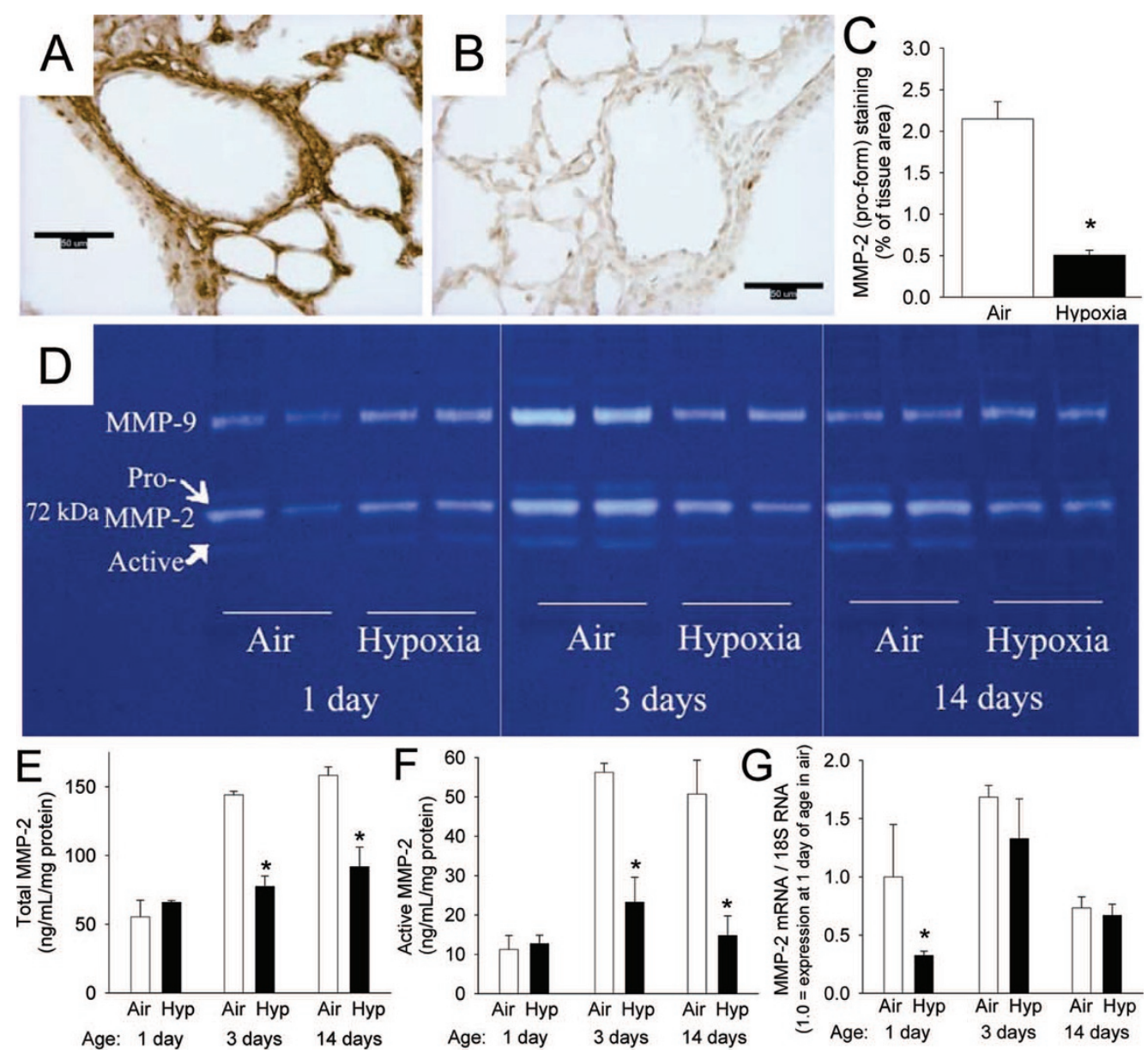

Figure 1. MMP-2 in the developing postnatal WT mouse lung and the effects of hypoxia $\left(12 \% \mathrm{O}_{2}\right)$. $(A, B)$ Immunohistochemical staining for proMMP-2 (brown) in lung sections from $14 \mathrm{~d}$ mice exposed to $(A)$ air or $(B)$ hypoxia (magnification, $\times 400$; calibration bars $=50 \mu \mathrm{m}$ ). $(C)$ Pro-MMP-2 staining quantitation as percent of tissue area $(n=6$ mice/gp; mean $\pm \mathrm{SE}$; $*<<0.001)$. (D) Zymogram of lung extracts from mice exposed to air or hypoxia for 1,3 , and $14 \mathrm{~d}$ from birth. (E) Total MMP-2 measured by ELISA from lung extracts of mice exposed to air or hypoxia (Hyp) from $1 \mathrm{~d}$ for up to $14 \mathrm{~d}(n=6 \mathrm{mice} / \mathrm{gp}$; mean \pm SE, ${ }^{*} p<0.05 v s$ air at same time point). (F) Active MMP-2 measured by ELISA from same samples as $E(n=6$ mice/gp; mean \pm SE, * $p<0.05 v s$ air at same time point). (G) Mmp 2 mRNA by competitive real-time PCR in homogenized lungs from mice exposed to air or hypoxia from $1 \mathrm{~d}$ for up to $14 \mathrm{~d}(n=6 \mathrm{mice} / \mathrm{gp}$; mean $\pm \mathrm{SE}, * p<0.05 v s$ air at same time point).

A

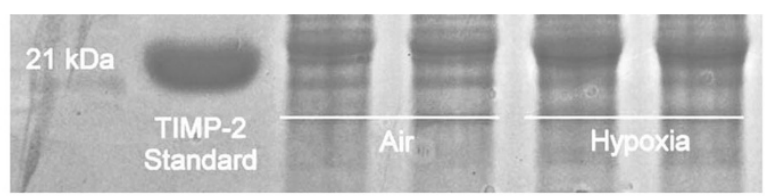

B

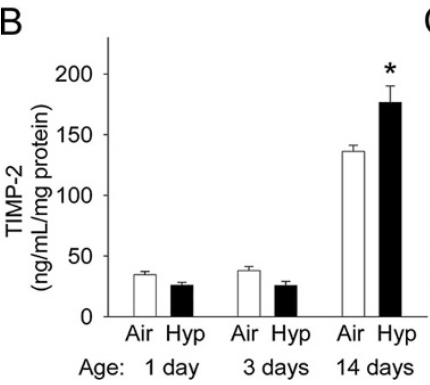

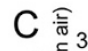

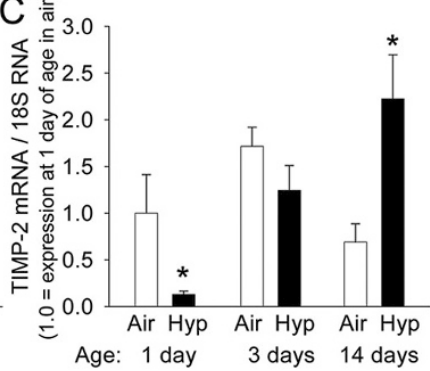

Figure 2. TIMP-2 in the developing postnatal WT mouse lung and the effects of hypoxia. (A) Reverse zymogram for TIMPs in lung extracts from $14 \mathrm{~d}$ mice exposed to air or hypoxia from birth. $(B)$ Densitometric quantitation of reverse zymograms for TIMP-2 from lung extracts of mice exposed to air or hypoxia (Hyp) from $1 \mathrm{~d}$ up to $14 \mathrm{~d}(n=6$ mice/gp; mean $\pm \mathrm{SE}, * p<0.05 v s$ air at same time point). (C) Timp 2 mRNA by competitive real-time PCR in homogenized lungs from mice exposed to air or hypoxia from $1 \mathrm{~d}$ up to $14 \mathrm{~d}$ ( $n=6$ mice/gp; mean $\pm \mathrm{SE}, * p<0.05 v s$ air at same time point).
4-12 $\mathrm{mm} \mathrm{Hg}$ ), and the RV/LV ratios (data not shown) were comparable with WT mice.

MMP-2 deficiency increases pulmonary arterial collagen and elastin. At $14 \mathrm{~d}$ of age, WT mice in air had collagen primarily in the perivascular region (Fig. 5A). Hypoxic WT mice had increased collagen (Fig. $5 B$ and E). $M m p 2^{-1-}$ air mice had increased collagen compared with WT air or WT hypoxia mice (Fig. $5 C$ and $E$ ), and hypoxia did not further increase collagen in $\mathrm{Mmp2}^{-1-}$ mice (Fig. $5 D$ and $E$ ).

At $14 \mathrm{~d}$ of age, WT mice in air had elastin primarily in the elastic laminae (Fig. 6A); hypoxic WT mice had increased elastin (Fig. $6 B$ and $E$ ). $M m p 2^{-1-}$ air mice had increased elastin compared with WT air or WT hypoxia mice (Fig. $6 C$ and $E$ ), and hypoxia further increased elastin in $M m p 2^{-1-}$ mice (Fig. $6 D$ and $E$ ).

\section{DISCUSSION}

The main findings of our study are that chronic hypoxia reduced active MMP-2 in lungs of neonatal mice and resulted in phenotypic changes (thicker-walled pulmonary arteries and collagen and elastin accumulation) similar to those seen in 


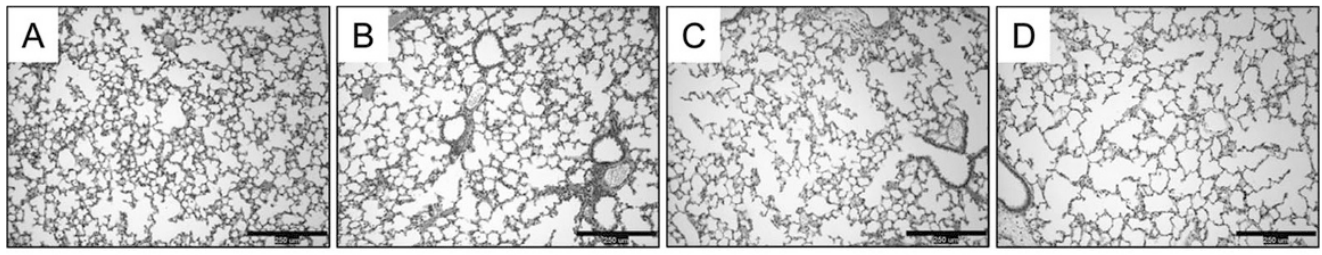

$\mathrm{E}$
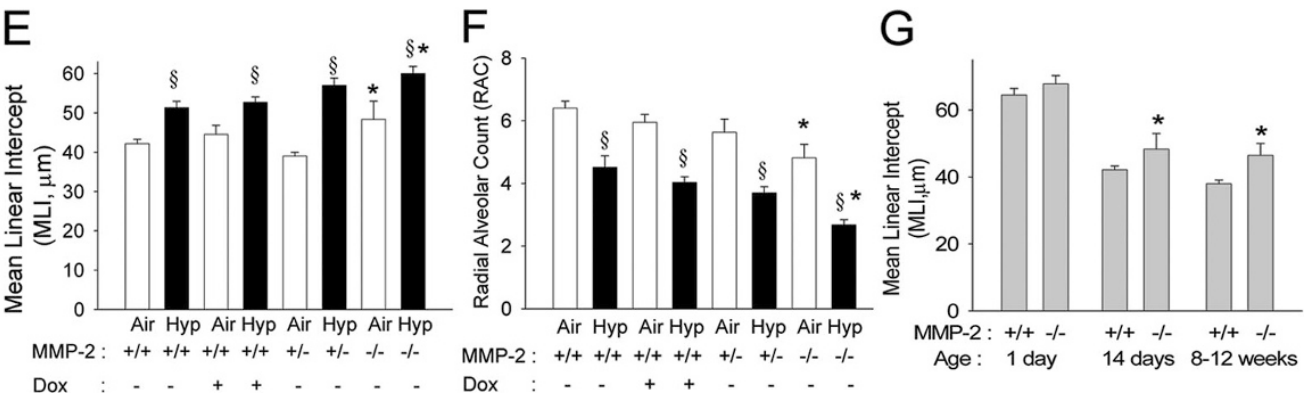

Figure 3. MMP-2 and alveolar development in WT and $M m p 2^{-1-}$ mice. $(A-D)$ Representative photomicrographs of mouse lungs from WT (A, B) and $M m p 2^{-l-}$ mice $(C, D)$ after $14 \mathrm{~d}$ of air $(A, C)$ or hypoxia $(B, D)$ exposure (magnification, $\times 100$; calibration bars $\left.=250 \mu \mathrm{m}\right)$. Alveoli are small and well developed with many secondary crests in WT air mice $(A)$, large with fewer secondary crests in WT hypoxia mice $(B)$ and $M m p 2^{-1-}$ air $(C)$ mice, and are much larger with minimal septation in $M m p 2^{-1-}$ hypoxic mice $(D) .(E)$ MLI and $(F)$ RAC at $14 \mathrm{~d}$ of age in WT $(+/+)$ mice given either vehicle or doxycycline (Dox), $\mathrm{Mmp2}^{+/-}$, and $\mathrm{Mmp2}^{-/-}$mice after air and hypoxic (Hyp) exposure (mean \pm SE; $n=6$ mice/gp; * $p<0.05 v s$ corresponding WT controls, $\$ p<0.05 v s$ corresponding air). $(G)$ MLI in WT and $M m p 2^{-1-}$ mice at $1 \mathrm{~d}, 14 \mathrm{~d}$, and $8-12$ wk of age (mean $\pm \mathrm{SE} ; n=6 \mathrm{mice} / \mathrm{gp} ; * p<0.05$ vs WT at same time point).

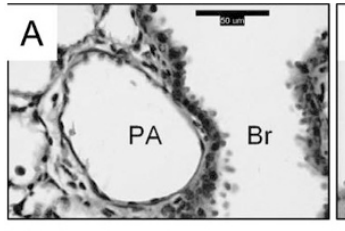

$\mathrm{E}$

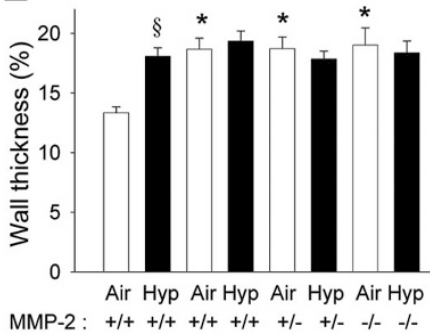

MMP-2: +/+ +/+ +/+ +/+ +/- +/- -/- - -

Dox

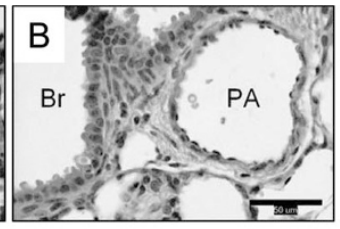

$\mathrm{F}$

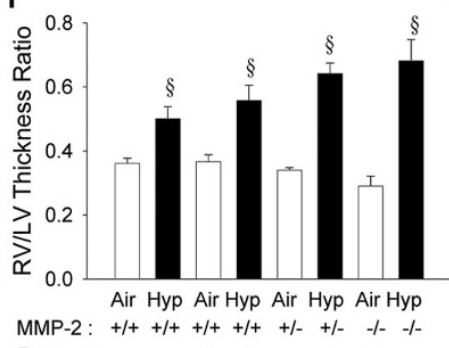

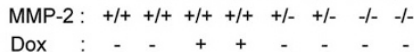

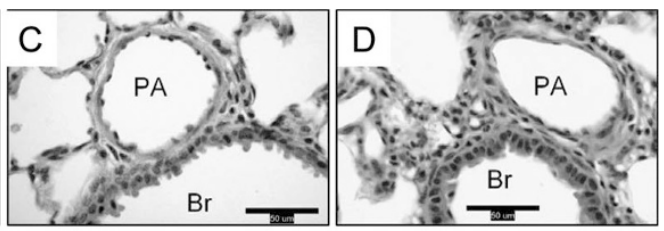

G

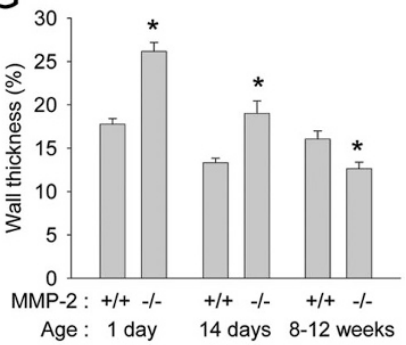

Figure 4. MMP-2 and pulmonary arterial remodeling in WT and $M m p 2^{-1-}$ mice. $(A-D)$ Representative photomicrographs of mouse lung pulmonary arteries from WT $(A, B)$ and $M m p 2^{-/-}$mice $(C, D)$ after $14 \mathrm{~d}$ of air $(A, C)$ or hypoxic $(B, D)$ exposure (magnification, $\times 400$; calibration bars $=50 \mu \mathrm{m}$; PA, pulmonary artery; $\mathrm{Br}$, bronchus). The wall thickness of the pulmonary artery is less in the WT air mice $(A)$ than in WT hypoxia $(B), M m p 2^{-l-}$ air $(C)$, or $M m p 2^{-l-}$ hypoxic mice $(D)$. $(E)$ Wall thickness $(\%)$ of pulmonary arteries and $(F)$ right ventricle/left ventricle (RV/LV) thickness ratio at $14 \mathrm{~d}$ of age in WT mice given either vehicle or doxycycline (Dox), Mmp $2^{+/-}$, and $M m p 2^{-/-}$mice after air and hypoxic exposure (mean \pm SE; $n=6$ mice/gp; * $p<0.05 v s$ corresponding WT controls, $\$ p<0.05$ vs corresponding air). $(G)$ Wall thickness $(\%)$ in air exposed WT and Mmp2 $2^{-1-}$ mice at $1 \mathrm{~d}, 14 \mathrm{~d}$, and $8-12 \mathrm{wk}$ of age (mean $\pm \mathrm{SE} ; n=$ 120 vessels/gp; $* p<0.05$ vs WT at same time point).

$M m p 2^{-1-}$ mice in air. Mmp $2^{-/-}$mice exposed to hypoxia had no further increase in pulmonary arterial thickness or collagen. These results suggest that a hypoxia-mediated reduction in MMP-2 activity may contribute to attenuation of normal postnatal pulmonary arterial remodeling. We also found that hypoxia increased lung TIMP-2 at 2 wk of age in WT mice, which may contribute to reduced MMP-2 activity. Our study also demonstrates a disconnect between pulmonary arterial remodeling and RV hypertrophy in $M m p 2^{-1-}$ mice. These results generate the hypothesis that over-expression or increased activation of MMP-2 can attenuate both hypoxia- induced pulmonary arterial thickening and impaired alveolarization.

Our study is the first to establish that MMP-2 deficiency results in thicker-walled pulmonary arteries and increased vascular collagen and elastin accumulation in newborn mice. Postnatally, pulmonary arteries remodel and become thinner in air-exposed mice. This process is inhibited by hypoxia, leading to persistent fetal-like, thicker-walled arteries. Conversely, in adult animals, hypoxic pulmonary arterial remodeling is an active process in which normally thin vessels accumulate matrix. In adult rodents, hypoxia increases 


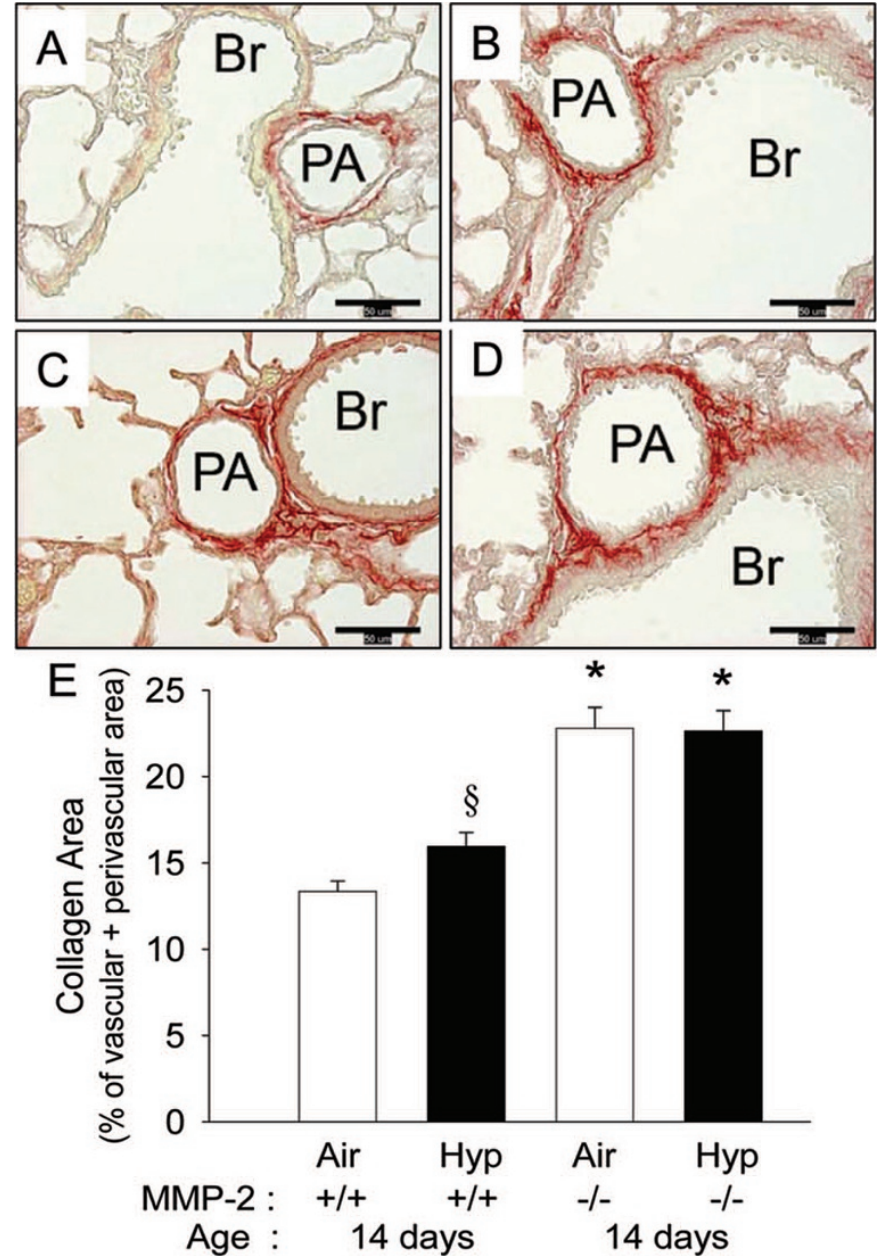

Figure 5. Perivascular collagen in $14 \mathrm{~d}$ WT and $M m p 2^{-1-}$ mice. $(A-D)$ Representative photomicrographs of picric acid-Sirius red stained sections (collagen is stained red) of pulmonary arteries from WT $(A, B)$ and $M m p 2^{-/-}$ mice $(C, D)$ after $14 \mathrm{~d}$ of air $(A, C)$ or hypoxic $(B, D)$ exposure (magnification, $\times 400$; calibration bars $=50 \mu \mathrm{m}$; PA, pulmonary artery; $\mathrm{Br}$, bronchus). Collagen in the perivascular area is least in the WT air mice $(A)$, increased in WT hypoxia $(B)$, and further increased in $M m p 2^{-1-}$ air $(C)$ and in $M m p 2^{-1-}$ hypoxic mice $(D)$. $(E)$ Collagen area measured by quantitative image analysis at $14 \mathrm{~d}$ of age in WT and $M m p 2^{-1-}$ mice after air and hypoxic exposure (mean $\pm \mathrm{SE} ; n=6$ mice/gp; $* p<0.05$ vs corresponding WT controls, $\$ p<0.05 v s$ corresponding air).

MMP-2 in pulmonary arteries (17) and lung extracts (30), and MMP-2 inhibition attenuates hypoxic pulmonary vascular remodeling (11). In contrast, our results in newborn mice demonstrated that not only did hypoxia prevent normal increases of MMP-2 but also that MMP-2 absence and inhibition slowed normal remodeling with persistence of thicker-walled pulmonary arteries.

Interestingly, the abnormal pulmonary arterial remodeling in newborn $\mathrm{Mmp2}^{-1-}$ mice in air was not associated with RV hypertrophy and did not persist into adult life. It is possible that the increased pulmonary arterial wall thickness may have led to lower compliance without increases in vascular resistance and pulmonary hypertension. Rosiglitazone-treated hypoxic adult rats have increased MMP-2 in pulmonary arteries and decreased arterial remodeling, without a reduction in pulmonary hypertension, indicating a disconnect between pulmonary arterial thickening and pulmonary hypertension (31).
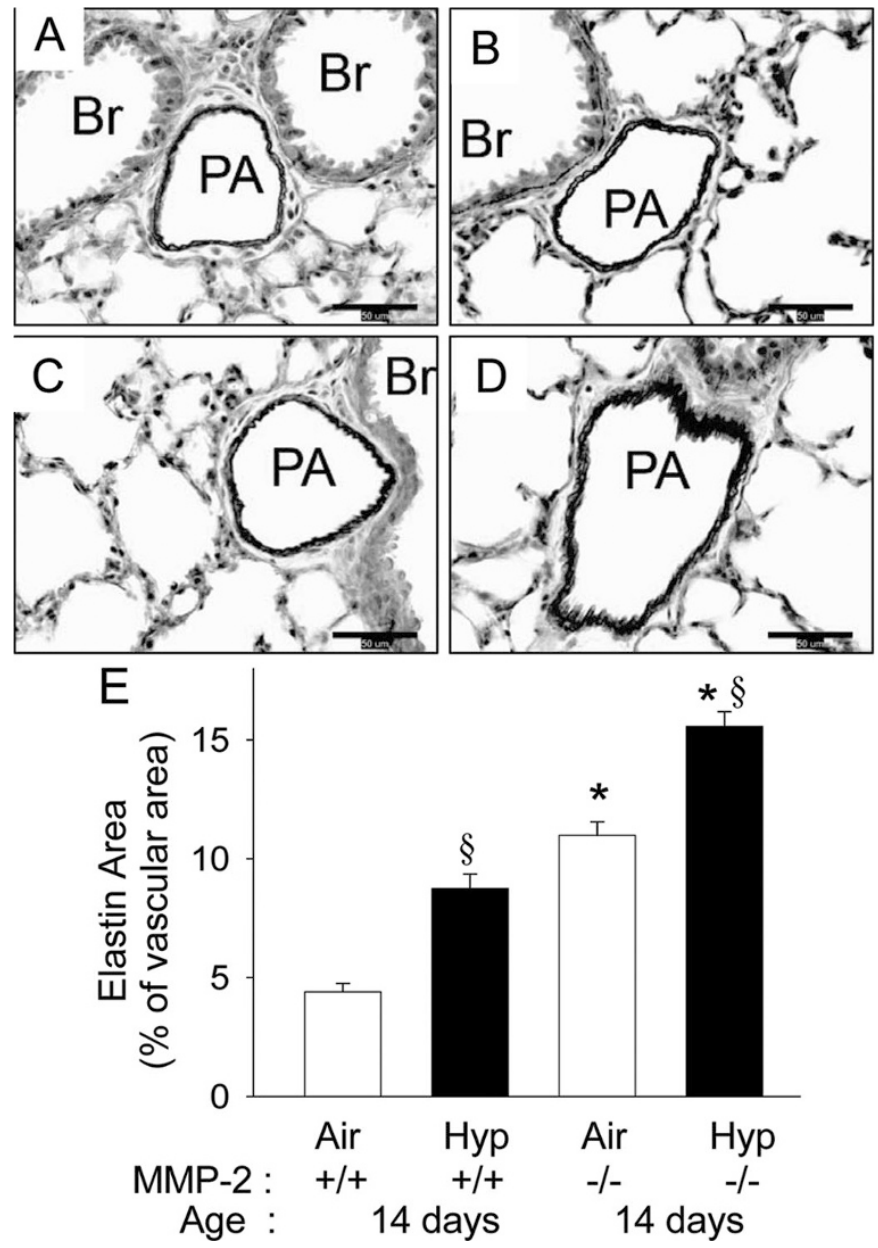

Figure 6. Vascular elastin in $14 \mathrm{~d}$ WT and $M m p 2^{-1-}$ mice. $(A-D)$ Representative photomicrographs of elastic tissue stained sections (elastin is stained black) of pulmonary arteries from WT $(A, B)$ and $M m p 2^{-1-}$ mice $(C, D)$ after $14 \mathrm{~d}$ of air $(A, C)$ or hypoxia $(B, D)$ exposure (magnification, $\times 400$; calibration bars $=50 \mu \mathrm{m}$; PA, pulmonary artery; Br, bronchus). Elastin is least in the WT air mice $(A)$, increased in WT hypoxia $(B)$, further increased in $\mathrm{Mmp2}^{-/-}$air $(C)$, and is maximal in $M m p 2^{-1-}$ hypoxic mice $(D)$. $(E)$ Elastin area measured by quantitative image analysis at $14 \mathrm{~d}$ of age in WT and $M m p 2^{-1-}$ mice after air and hypoxic exposure (mean $\pm \mathrm{SE} ; n=6$ mice/gp; $* p<0.05$ vs corresponding WT controls, $\S p<0.05 v s$ corresponding air).

Our data also suggest a disconnect, but in the opposite direction: decreased MMP-2 in thicker-walled pulmonary arteries and no RV hypertrophy in newborn $M m p 2^{-1-}$ mice in air.

The fetal lung has a dominant proteolytic profile with high MMP-2, whereas the adult lung exhibits a more antiproteolytic profile with decreased MMP-2 (14). Thus, MMPs appear to play different roles in neonatal and adult hypoxia-induced pulmonary arterial remodeling. Hypoxic pulmonary arterial remodeling is more marked in neonatal compared with adult animals for the same degree of hypoxia (32). The results of this study add to these differences in underlying disease mechanisms.

Other investigators $(14,33)$ have evaluated MMP-2 in the developing lung during hypoxia. Gebb et al. (33) showed that MMP-2 by zymography was lower at $3 \%$ compared with $21 \%$ $\mathrm{O}_{2}$ in fetal rat lung explants despite no change in MMP-2 mRNA levels, indicating that hypoxia suppressed MMP-2 
activity at the postmRNA level. Ryu et al. (14) subjected neonatal (P2) and adult CD-1 mice to $2 \mathrm{wk}$ of hypoxia and showed that neonatal, but not adult, mouse lungs had moderately increased total MMP-2 by Western blot, although proMMP-2 by ELISA was not different. These results differ from those of our study and of Gebb et al. (33), perhaps because of differences in methods. It is possible that MMP-2 activity may have decreased without changes in pro-MMP-2 levels in the study by Ryu et al. (14).

$M m p 2^{-1-}$ mice had more perivascular collagen deposition than WT mice exposed to either air or hypoxia, indicating that MMP-2 is involved in vascular collagen turnover. The excess perivascular collagen may not contribute to pulmonary vascular resistance because $M m p 2^{-1-}$ mice in air do not have RV hypertrophy. Hypoxia increased perivascular collagen in WT mice, likely because of hypoxia-induced reductions in MMP-2 and collagen turnover. We have shown recently that increased perivascular collagen in the lung of hypoxia-exposed WT neonatal mice is primarily the result of decreased turnover because collagen mRNA expression does not increase, whereas elastin accumulation is the result of both increased gene expression and reduced turnover (28). Vascular elastin levels were greater in $M m p 2^{-1-}$ than in WT mice under air conditions, consistent with the data indicating MMP-2 degrades elastin (15). Increased elastin in hypoxic $M m p 2^{-/-}$ mice indicates that mechanisms independent of MMP-2 regulate elastin during hypoxia. We have reported that an increase in endothelin-1 with hypoxia decreases collagen turnover and increases elastin expression (28), indicating that endothelin-1 and MMP-2 may interact in modulating ECM changes with hypoxia.

Our study adds to the body of evidence implicating MMPs in alveolar development. Alveolar development in the $\mathrm{Mmp}^{-1-}$ and Mmp $14^{-1-}$ mice is abnormal despite normally branching morphogenesis (34,35). Atkinson et al. (35) suggested that the impaired alveolarization in the $M m p 2^{-/-}$ mouse was transient, although our results indicate that, although modest, these mice do not have fully normal alveolarization even at 8-12 wk. Adult Timp $2^{-/-}$mice have a relatively normal phenotype despite no MMP-2 activation (36), but transient changes may have occurred in the first 2 weeks of age. We observed that doxycycline administration as well as $M m p 2^{+/-}$genotype, associated with partial MMP-2 inhibition, led to arterial remodeling but did not inhibit alveolarization. This disconnect in findings between partial and total MMP-2 inhibition suggests a threshold effect in which arterial thickening is more dependent on MMP-2 activity than is alveolar development. We speculate that this may be related to the increased ECM in pulmonary arteries compared with the alveoli or the predominance of MMP-2 compared with MMP-9 in the vasculature.

Our study is clinically relevant because we observed that MMP-2 absence leads to inhibited alveolarization and abnormal arterial remodeling, characteristics of BPD (37). Low MMP-2 in preterm infant airways is associated with subsequent BPD (38), and our study suggests that reductions in MMP-2 are not just a prognostic marker but may also be a contributor to the pathogenesis of BPD. Limita- tions of our study include the use of a newborn mouse model, which may not closely resemble the human equivalent, and the analysis of whole lung homogenates, which does not identify the cells responsible for the abnormalities in arterial and alveolar development. Further support for a key role of MMP-2 in mediating effects of hypoxia on the newborn lung would require the use of MMP-2 overexpression systems to evaluate prevention or reversal of hypoxia-induced abnormalities in arterial remodeling and alveolarization.

\section{REFERENCES}

1. Haworth SG, Hislop AA 2003 Lung development-the effects of chronic hypoxia. Semin Neonatol 8:1-8

2. Walsh-Sukys MC 1993 Persistent pulmonary hypertension of the newborn. The black box revisited. Clin Perinatol 20:127-143

3. Goodman G, Perkin RM, Anas NG, Sperling DR, Hicks DA, Rowen M 1988 Pulmonary hypertension in infants with bronchopulmonary dysplasia. J Pediatr 112:67-71

4. Hoffmeister HM, Apitz J, Hoffmeister HE, Fischbach H 1981 The correlation between blood pressure and morphometric findings in children with congenital heart disease and pulmonary hypertension. Basic Res Cardiol 76:647656

5. Steinhorn RH, Fineman JR 1999 The pathophysiology of pulmonary hypertension in congenital heart disease. Artif Organs 23:970-974

6. Blanco LN, Massaro D, Massaro GD 1991 Alveolar size, number, and surface area: developmentally dependent response to 13\% O2. Am J Physiol 261:L370L377

7. Massaro D, Massaro GD 2002 Invited review: pulmonary alveoli: formation, the "call for oxygen," and other regulators. Am J Physiol Lung Cell Mol Physiol 282:L345-L358

8. Thurlbeck WM 1975 Postnatal growth and development of the lung. Am Rev Respir Dis 111:803-844

9. Burri P. 1997 Structural aspects of prenatal and postnatal development and growth for the lung. In: McDonald JA (ed) Lung Growth and Development. Dekker, New York, pp 1-35

10. Stetler-Stevenson WG, Yu AE 2001 Proteases in invasion: matrix metalloproteinases. Semin Cancer Biol 11:143-152

11. Herget J, Novotna J, Bibova J, Povysilova V, Vankova M, Hampl V 2003 Metalloproteinase inhibition by Batimastat attenuates pulmonary hypertension in chronically hypoxic rats. Am J Physiol Lung Cell Mol Physiol 285:L199L208

12. Mackay AR, Hartzler JL, Pelina MD, Thorgeirsson UP 1990 Studies on the ability of $65-\mathrm{kDa}$ and $92-\mathrm{kDa}$ tumor cell gelatinases to degrade type IV collagen. J Biol Chem 265:21929-21934

13. Fukuda Y, Ishizaki M, Okada Y, Seiki M, Yamanaka N 2000 Matrix metalloproteinases and tissue inhibitor of metalloproteinase-2 in fetal rabbit lung. Am J Physiol Lung Cell Mol Physiol 279:L555-L561

14. Ryu J, Vicencio AG, Yeager ME, Kashgarian M, Haddad GG, Eickelberg O 2005 Differential expression of matrix metalloproteinases and their inhibitors in human and mouse lung development. Thromb Haemost 94:175-183

15. Senior RM, Griffin GL, Fliszar CJ, Shapiro SD, Goldberg GI, Welgus HG 1991 Human 92- and 72-kilodalton type IV collagenases are elastases. J Biol Chem 266:7870-7875

16. Pardo A, Selman M 1996 Matrix metalloproteinases and lung injury. Braz J Med Biol Res 29:1109-1115

17. Frisdal E, Gest V, Vieillard-Baron A, Levame M, Lepetit H, Eddahibi S, Lafuma C, Harf A, Adnot S, Dortho MP 2001 Gelatinase expression in pulmonary arteries during experimental pulmonary hypertension. Eur Respir J 18:838845

18. Murphy G, Stanton H, Cowell S, Butler G, Knauper V, Atkinson S, Gavrilovic J 1999 Mechanisms for pro matrix metalloproteinase activation. APMIS 107:38-44

19. Nagase H 1998 Cell surface activation of progelatinase A (proMMP-2) and cell migration. Cell Res 8:179-186

20. Corcoran ML, Hewitt RE, Kleiner DE, Jr. Stetler-Stevenson WG 1996 MMP-2: expression, activation and inhibition. Enzyme Protein 49:7-19

21. Butler GS, Butler MJ, Atkinson SJ, Will H, Tamura T, van Westrum SS, Crabbe T, Clements J, d'Ortho MP, Murphy G 1998 The TIMP-2 membrane type 1 metalloproteinase "receptor" regulates the concentration and efficient activation of progelatinase A. A kinetic study. J Biol Chem 273:871-880

22. Ambalavanan N, Bulger A, Murphy-Ullrich J, Oparil S, Chen YF 2005 Endothelin-A receptor blockade prevents and partially reverses neonatal hypoxic pulmonary vascular remodeling. Pediatr Res 57:631-636

23. Itoh T, Ikeda T, Gomi H, Nakao S, Suzuki T, Itohara S 1997 Unaltered secretion of beta-amyloid precursor protein in gelatinase A (matrix metalloproteinase 2)-deficient mice. J Biol Chem 272:22389-22392

24. Manning MW, Cassis LA, Daugherty A 2003 Differential effects of doxycycline, a broad-spectrum matrix metalloproteinase inhibitor, on angiotensin II-induced ath- 
erosclerosis and abdominal aortic aneurysms. Arterioscler Thromb Vasc Biol 23:483-488

25. Brey EM, Lalani Z, Johnston C, Wong M, McIntire LV, Duke PJ, Patrick CW Jr. 2003 Automated selection of DAB-labeled tissue for immunohistochemical quantification. J Histochem Cytochem 51:575-584

26. McGowan S, Jackson SK, Jenkins-Moore M, Dai HH, Chambon P, Snyder JM 2000 Mice bearing deletions of retinoic acid receptors demonstrate reduced lung elastin and alveolar numbers. Am J Respir Cell Mol Biol 23:162-167

27. Cooney TP, Thurlbeck WM 1982 The radial alveolar count method of Emery and Mithal: a reappraisal 1; postnatal lung growth. Thorax 37:572-579

28. Ambalavanan N, Li P, Bulger A, Murphy-Ullrich J, Anderson PG, Oparil S, Chen YF 2007 Endothelin-1 mediates hypoxia-induced increases in vascular collagen in the newborn mouse lung. Pediatr Res 61:559-564

29. Miller AP, Feng W, Xing D, Feng W, Weathington NM, Blalock JE, Chen YF, Oparil S 2004 Estrogen modulates inflammatory mediator expression and neutrophil chemotaxis in injured arteries. Circulation 110:1664-1669

30. Zaidi SH, You XM, Ciura S, Husain M, Rabinovitch M 2002 Overexpression of the serine elastase inhibitor elafin protects transgenic mice from hypoxic pulmonary hypertension. Circulation 105:516-521

31. Crossno JT Jr, Garat CV, Reusch JE, Morris KG, Dempsey EC, McMurtry IF, Stenmark KR, Klemm DJ 2007 Rosiglitazone attenuates hypoxia-induced pulmonary arterial remodeling. Am J Physiol Lung Cell Mol Physiol 292:L885-L897
32. Rabinovitch M, Gamble WJ, Miettinen OS, Reid L 1981 Age and sex influence on pulmonary hypertension of chronic hypoxia and on recovery. Am J Physiol 240:H62-H72

33. Gebb SA, Fox K, Vaughn J, McKean D, Jones PL 2005 Fetal oxygen tension promotes tenascin-C-dependent lung branching morphogenesis. Dev Dyn 234:1-10

34. Kheradmand F, Rishi K, Werb Z 2002 Signaling through the EGF receptor controls lung morphogenesis in part by regulating MT1-MMP-mediated activation of gelatinase A/MMP2. J Cell Sci 115:839-848

35. Atkinson JJ, Holmbeck K, Yamada S, Birkedal-Hansen H, Parks WC, Senior RM 2005 Membrane-type 1 matrix metalloproteinase is required for normal alveolar development. Dev Dyn 232:1079-1090

36. Caterina JJ, Yamada S, Caterina NC, Longenecker G, Holmback K, Shi J, Yermovsky AE, Engler JA, Birkedal-Hansen H 2000 Inactivating mutation of the mouse tissue inhibitor of metalloproteinases-2 (Timp-2) gene alters proMMP-2 activation. J Biol Chem 275:26416-26422

37. Coalson JJ 2003 Pathology of new bronchopulmonary dysplasia. Semin Neonatol 8:73-81

38. Danan C, Jarreau PH, Franco ML, Dassieu G, Grillon C, Abd Alsamad I, Lafuma C, Harf A, Delacourt C 2002 Gelatinase activities in the airways of premature infants and development of bronchopulmonary dysplasia. Am J Physiol Lung Cell Mol Physiol 283:L1086-L1093 